\title{
Review on Mitigation of Welding-Induced Distortion Based on FEM Analysis
}

\author{
Chunbiao $\mathrm{Wu}^{*}$ and Jae-Woong Kim**,, \\ *Department of Mechanical Engineering, Graduate School of Yeungnam University, \\ Gyeongsan, 38541, Korea \\ **School of Mechanical Engineering, Yeungnam University, Gyeongsan, 38541, Korea \\ †Corresponding author : jaekim@ynu.ac.kr \\ (Received April 11, 2019 ; Revised April 24, 2019 ; Accepted September 23, 2019)
}

\begin{abstract}
Welding distortion is an unavoidable issue due to localized expansion and contraction during the heating and cooling cycles, and has a negative effect on the fabrication process. However, mitigating weld distortion to meet product requirements is a challenging task, because welding shrinkage can't be prevented, only controlled. This paper provides a comprehensive literature review of various techniques to reduce and optimize the deformation induced by welding in the design stage and manufacturing process. Finite element numerical analysis methods are usually employed to predict welding distortion, and can cost less than actual experiments. The review of these approaches is useful to fully understand the main mechanisms used to mitigate weldinginduced distortion, and for choosing the most suitable method to minimize deformation based on realistic fabrication requirements.
\end{abstract}

Key Words : Welding distortion, Optimization, FEM analysis, Welding process, Welding sequence; Artificial intelligence, Mechanical and thermal balance control method

\section{Introduction}

Welding is considered as one of the most efficient, dependable and economical means of fabrication to join metals permanently ${ }^{1}$. It is widely used in various engineering application such as automotive, shipbuilding, aerospace, construction, gas and oil trucks, nuclear and thermal power plants, pressure vessels, heavy and earthmoving equipment ${ }^{2}$. However, welding-induced distortions are usually formed in the whole welded structures, which is attributed to the localized expansion and contraction during the heating and cooling cycle of the welding process. Welding deformation plays a negative role in the fabrication process, which can have a significant impact on several ways, such as the accuracy of assembly, external appearance, additional quality cost and various strength of the welded structure ${ }^{2,3)}$. Therefore, it is very important to accurately predict and mitigate welding-induced distortion both in design and manu- facturing procedure.

In order to predict welding distortion, thermal elastic-plastic finite element method (TEP-FEM) has been become a useful tool since first proposed by Ueda et el. in $1971^{4}$. Over the last two decades, a large amount of TEP-FEM models have developed to accurately predict welding deformation in various kinds of welded structures with experiment verification ${ }^{5-9}$. D. Deng et al. ${ }^{5}$ presented a numerical model based on thermal elastic plastic finite element method to investigate welding distortion in low carbon steel thin-plate bead-on joints. C. Wang et al. ${ }^{6}$ developed a more accurate model to predict angular distortion and longitudinal bending of the T-joint weld. A three-dimensional TEP-FEM numerical model has been established to simulate welding process during single-pass welding of pipes proposed by $\mathrm{C}$. $\mathrm{Wu}$ et $\mathrm{al}^{8}{ }^{8}$. Experiments were also carried out to verify all of the FE numerical model. Although conventional TEP-FEM analysis is effective tool to obtain high precision results, it is difficult to apply to large welded 
structure because of the excessive computational time and $\operatorname{costs}^{10)}$.

In order to reduce the computation time, elastic FEM analysis based on inherent strain has been frequently used to predict welding deformation in large welded structure. The two commonly used methods are inherent deformation method ${ }^{11-13)}$ and strain as direct boundary (SDB) method ${ }^{14-16)}$, respectively. D. Deng et al. ${ }^{11)}$ proposed an elastic finite element method, based on inherent deformation theory, to precisely predict welding distortion during the assembly process of large structure considering both local shrinkage and root gap. Y. Ha et al. ${ }^{14)}$ developed a new approach, based on equivalent thermal strain like strain as direct boundary (SDM method), to predict the welding distortion of large hull block. Compared with experiments results, the accuracy of elastic FEM analysis models based on inherent strain is verified.

Generally speaking, the welding-induced distortion can be classified into out-of-plate and in-plate deformation mode. Out-of-plane welding distortion includes bending distortion and buckling distortion. And in-plane welding deformation results from longitudinal and transverse shrinkage. Various types of weld distortion in a welded structure are shown in Fig. $1^{17)}$.

Mitigation of weld distortion to meet product requirements is a challenging task, because welding shrinkage can't be prevented, but just can be controlled. So far, many researchers have proposed various effective methods to minimize weld deformation. In general, there are three main patterns to solve the weld distortion problems during structure and fabrication design stage, manufacturing stage and final distortion correction, respectively. Detailed classifications are shown in Fig. 2.

In this paper, a comprehensive literature review on various techniques to reduce and optimize the distortion induced by welding based on finite element method was

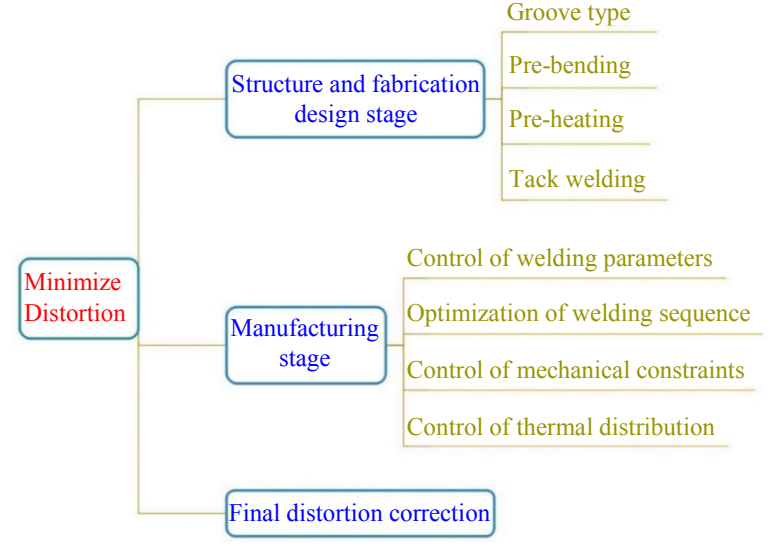

Fig. 2 Various approaches to mitigate welding distortion

presented. FEM numerical analysis can accurately predict welding distortion, which can spend less cost than actual experiments. In order to select the reasonable structure or fabrication design and welding process parameters for minimizing welding distortion, many efforts have been made in recent publications. Various algorithms for welding sequence optimization such as genetic algorithm (GA) and artificial neural network (ANN) are attempted to reduce deformation. Meanwhile, mechanical and thermal balance techniques during welding process are developed to control the welding distortion by reducing welding thermal gradients and generating a tensile stress field near the welded region. The review of these approaches would be useful to fully understand the main mechanism of mitigation of welding-induced distortion and to choose the most suitable method for minimizing deformation according to the realistic fabrication demand.

\section{Distortion control in the design stage}

At the design stage, welding distortion can often be

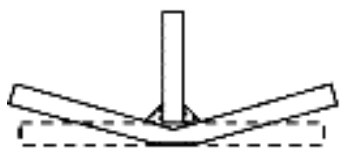

Angular deformation

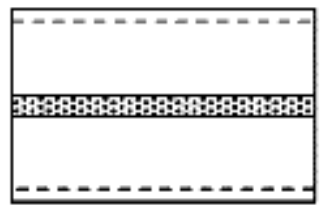

Transverse shrinkage

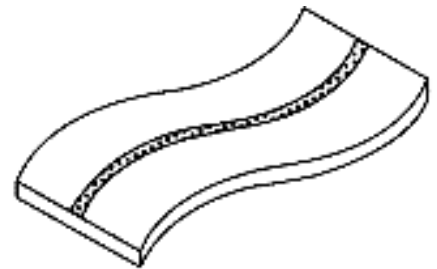

Buckling distortion

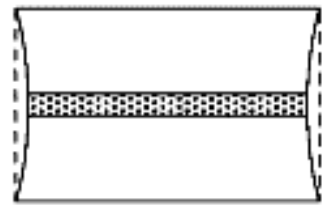

Longitudinal shrinkage

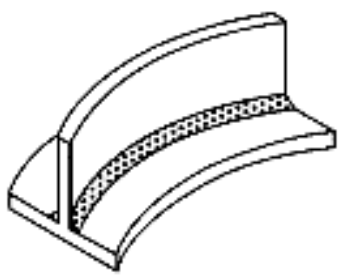

Longitudinal bending

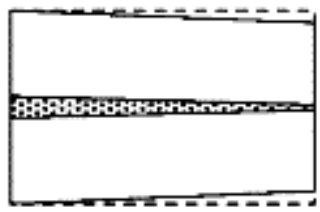

Rotational distortion

Fig. 1 Various types of weld distortion ${ }^{17)}$ 
prevented at the source of formation in welded structures. In general, important design-related variables and practices include type of weld joint, stiffener spacing, using balanced welding, selection of appropriate thickness, using construction technique properly and so on ${ }^{18)}$. Next, several common design are introduced for limiting welding distortion.

Groove welding is a common type of weld joint design, which can make a full penetration to achieve a strong connection in a thicker butt-welded joint. A groove between two pieces of metal should be machined prior to welding. There are various types of groove, such as, signle V-groove, double V-groove and U-groove etc. Y. Ye et al. ${ }^{19)}$ developed a 3-D TEP-FEM model to investigate the influence of groove type on welding-induced residual stress and deformation in a SUS304 steel butt welded joint. Three different groove types (i.e. V-groove, $\mathrm{K}$-groove and X-groove) were design. Meanwhile, experiments were carried out to validate proposes simulation model. The numerical results suggest that $\mathrm{X}$-groove is superior to $\mathrm{K}$-groove and $\mathrm{V}$-groove for limiting welding distortion, as shown in Fig. 3.

$\mathrm{V}, \mathrm{K}$ and $\mathrm{X}$ types are commonly used grooves of butt welded joints in heavy industry and shipbuilding. However, it is also necessary to pay attention to J-type and double J-type grooves. It is convenient to investigate their influence on welding deformation using 3D TEP-FEM analysis.

Not only groove types, but also groove designs have a great impact on welding distortion, such as the groove angle and groove size (weld deposition). It is possible to search the optimum value of groove designs to reduce the welding distortion. It's an economic approach to make an optimal groove designs before welding using 3D TEP-FEM analysis.

Next, application of tack welding is a highly effective approach to reduce distortion in the welded structures

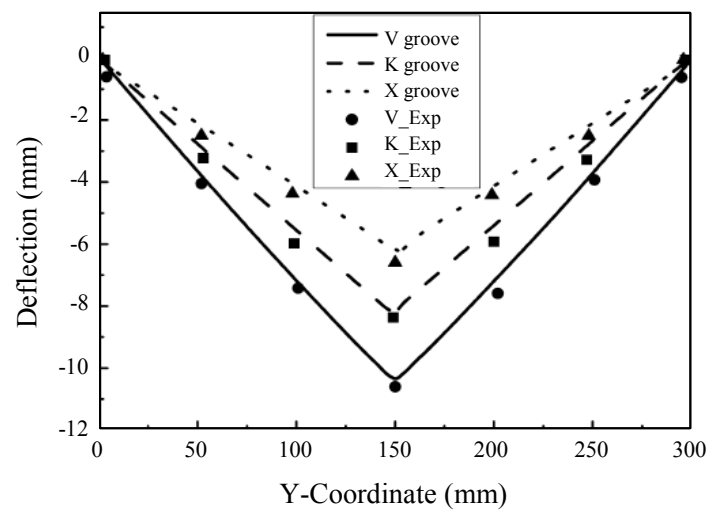

Fig. 3 Comparison of angular distortion among V, K and $\mathrm{X}$ groove joints ${ }^{19)}$ because of change of the stiffness of the component. D. Camilleri et al. ${ }^{20)}$ numerically investigated the influence of different tack welding fabrication procedures on the final deformations of seam welded plate structures. They proposed a fabrication procedure which leads to a minimal out-of-plane distortion depending on their experimental mock-up. M. Abid et al. ${ }^{21)}$ analyzed the effect of tack weld positions and root gap on welding distortions and residual stresses in a pipe-flange joint. They concluded that the axial displacement and the tilt of the flange face strongly depend on the tack weld orientation. C. Heinzea et al. ${ }^{22)}$ analysed the influence of tack welds on welding-induced distortion of flat steel plates using the numerical simulation. The numerical simulation results show that application tack welding in realistic fabrication conditions can reduce final distiortion $23 \%$ than the case neglecting tack welding. Therefore, it was recommended to use tack welding in welding process.

In addition, pre-heating or post-heating can also reduce welding distortion due to reducing the sharp temperature gradient during welding process. Pre-shaping method is another effective means of controlling angular distortion, which can be applied prior to welding. It includes pre-setting and pre-bending methods. The design of a structure is altered in such a way that after welding distortion, the preferred final shape will be achieved. Fig. 4 shows the results of this method used in design modification ${ }^{23)}$.

However, it is difficult to calculate the amount of pre-setting or pre-bending considering the welding inherent shrinkage. In general, a number of trial welding tests will be required. Fortunately, instead of trial welding experiments, it is possible to obtain an appropriate

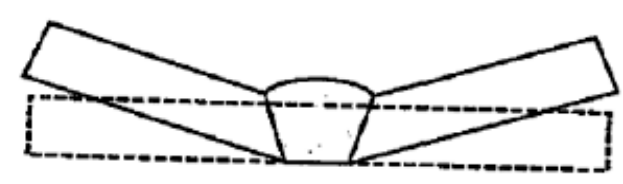

(b) conventional welding

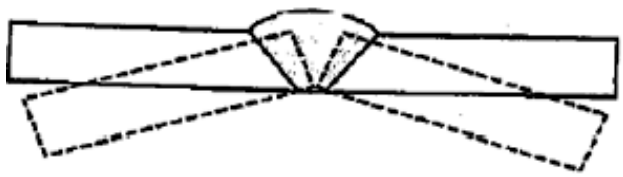

(c) pre-setting

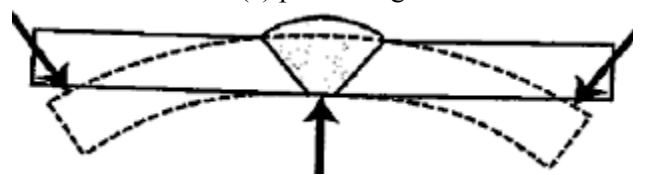

(a) pre-bending

Fig. 4 Pre-setting and pre-bending methods used in distortion reduction ${ }^{23)}$ 
value through TEP-FEM analysis.

Either groove design, tack welding or pre-setting and pre-bending method can select the optimal state to reduce welding distortion by using finite element analysis before welding.

\section{Welding process parameters control}

It is believed that choosing the optimum welding process parameters is a better approach to control the welding distortion. However, it isn't a simple task because this is a multiple input process of which a linear model cannot be established to solve such problem.

There are a lot of controllable process related parameters which could affect weld distortion during the welding process, as shown in Fig. 5. Among of these, the rather important process parameters include heat input (i.e. welding voltage, current and speed), weld sequence, weld procedure and control of thermal distribution.

Up to now, various techniques for the optimization of welding process parameters have been developed to predict the inter-relation between multi-input and output parameters. The conventional techniques, such as regression analysis, Taguchi experimental design and response surface methodology (RSM), are usually used to deal with the welding process control problems. For example, M.T. Hayajneh et al. ${ }^{24)}$ employed methods of design of experiments (DOE) and analysis of variance (ANOVA) to optimize the welding parameters for minimizing the bending distortion of I-beams fabricated from steel sheets using submerged arc welding, as show in Fig. 6. In this experiment, Welding arc voltage, wire feed speed, and welding travel speed are examined by performing three-level full factorial design in three blocks. A total of 81 experimental runs are carried out. The result shows that arc voltage and wire feed speed

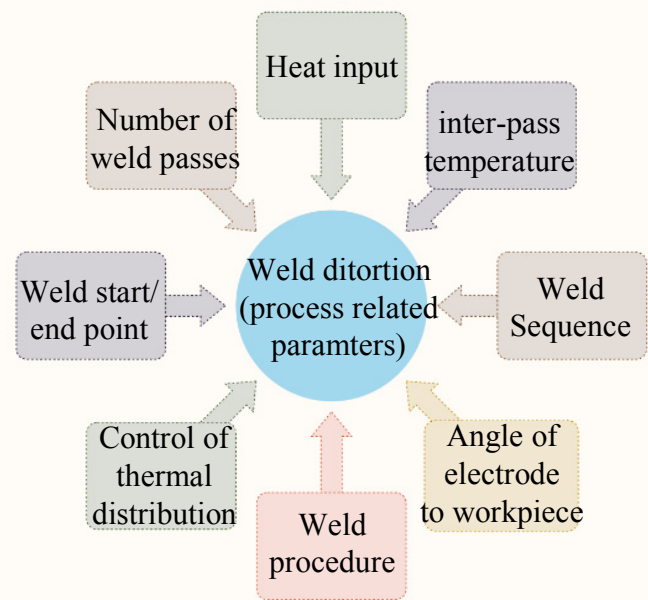

Fig. 5 Process related parameters affecting weld distortion

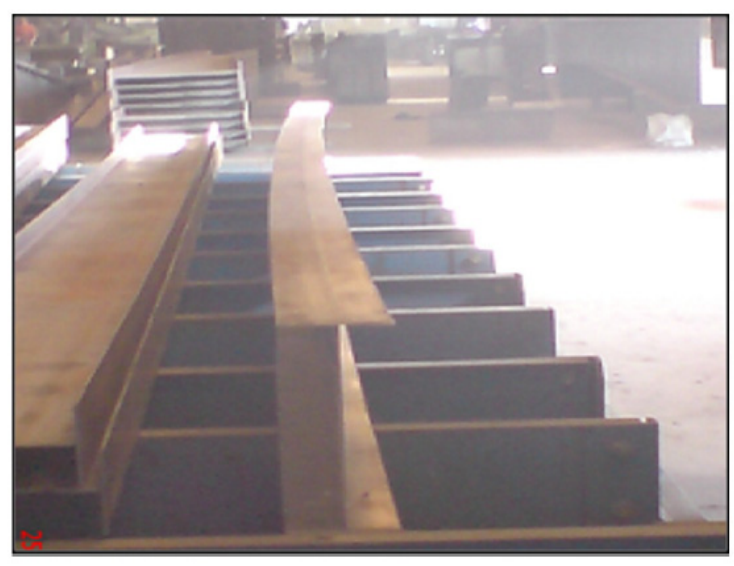

Fig. 6 Bending distortion of a welded I-beam ${ }^{24)}$

are the most significant factors, while travel speed shows less significance. Several sets of suitable input parameters can be chosen to minimize distortion and maximize productivity.

In addition, the mass number of parameters in the model increases the run time of the algorit $28 \mathrm{hms}$ so that evolutionary computational techniques are used for practical solution. For example, Genetic algorithm (GA) and Artificial Neural Network (ANN) are two representative and effective approaches which have been widely used to control the welding process.

M. Islam et al. ${ }^{25)}$ proposed an effective numerical approach for welding process parameter optimization to minimize weld-induced distortion in structures based on genetic algorithm. The proposed numerical design optimization system is illustrated in Fig. 7. In order to save cost and time of experiments, the weld distortion was predicted by using thermo-elastic-plastic FE analysis. The target of this study is an automotive suspension part (lower arm). The lower arm FE model is shown in Fig. 8.

The respond of welding distortion is controlled by four input parameters: welding speed (X1), arc voltage (X2), welding current (X3) and welding direction (X4), respectively. Total number of combination for four controllable parameters was $11520\left(6 \times 10 \times 4 \times 2^{3} \times 3\right.$ ! $)$. This problem with such many possible combinations can't handle with traditional methods. But we can achieve optimum results with a restriction of maximum $100 \mathrm{FE}$ simulations using GA. The best optimization results is about $20 \sim 40 \%$ less than the maximum total distortion of found by simulation.

In summary, both conventional methods and AI techniques can solve the optimum welding process parameters problems. There is no better or worse in terms of the two means. According to the number of parameters 


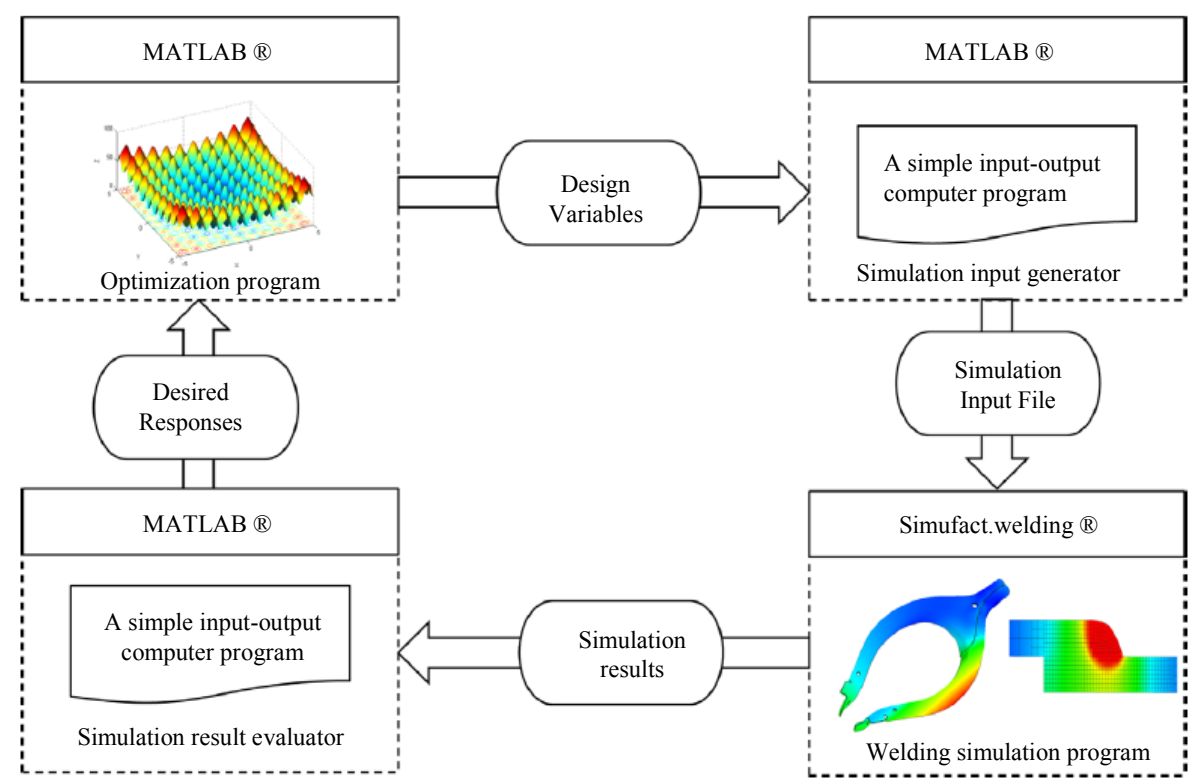

Fig. 7 Framework of numerical design optimization system ${ }^{25)}$

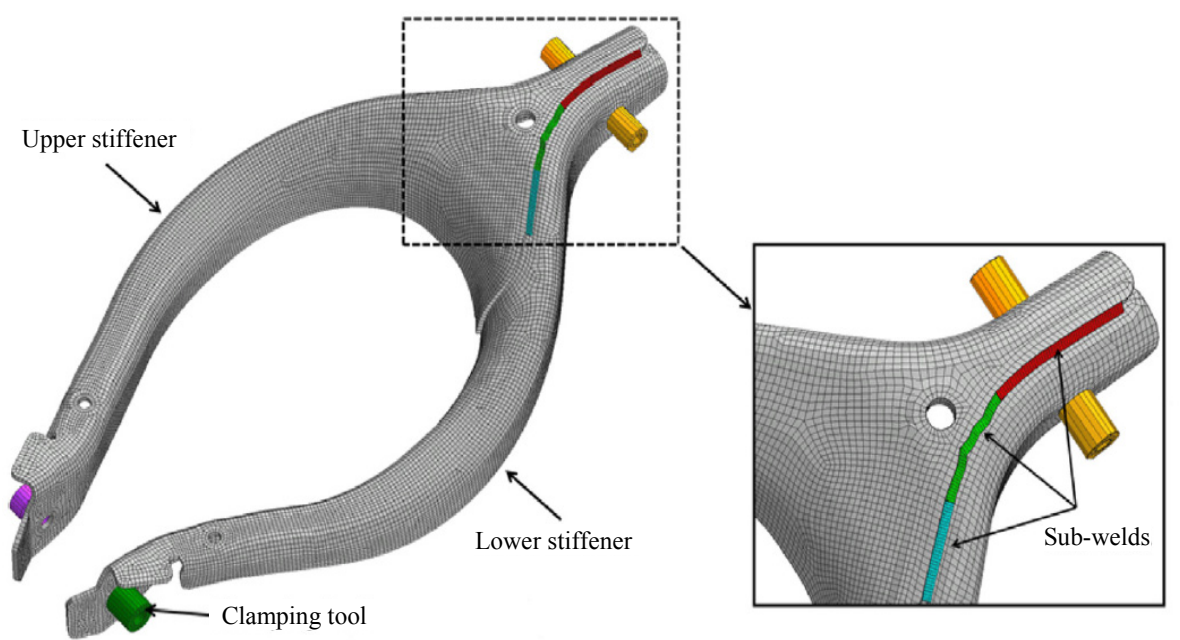

Fig. 8 3D FE model of lower arm specimen ${ }^{25)}$

in practical problems, a suitable parameter optimization method is selected to reduce welding distortion.

\section{Optimization of welding sequence}

For welded structures with many weld seams, welding sequence and direction are an important part of design and manufacturing process. The welding deposition sequences have a strong influences on the magnitude and deformation mode of the deflections ${ }^{26)}$. Therefore, selection of the optimal welding sequence is a simple and more efficient approach for reduction of welding distortion. The conventional approach is to select the relatively good sequence schemes with reasonable weld arrangement using TEP-FEM analysis, which often does not offer an optimal sequence ${ }^{27,28)}$.

In order to obtain the optimal welding sequence, the experiment is designed, based on a full factorial design. The corresponding independent controllable parameters are the number of weld beads and welding direction, respectively.

So the total numbers of welding configurations can be calculated by Eq. (1).

$$
N=n^{r} \times r !
$$

where $\mathrm{n}$ is the number of welding directions; $\mathrm{r}$ is the number of weld beads ; $\mathrm{N}$ is the total numbers of welding configurations.

The possible amount of experiments grows exponentially with the number of welding beads. For example, in this 
research we have used eight weld seams and two welding directions, hence the number of welding configurations for exhaustive search is $10,321,920$. Therefore, it is impossible to achieve the optimal welding sequence using experiments or finite element method, due to so many cases.

In order to overcome these limitations, researchers have made various attempts. Recently, many research works have implemented various artificial intelligence techniques to determine an optimal welding sequence, which includes genetic algorithm $(\mathrm{GA})^{29,30)}$, artificial neural network (ANN) ${ }^{31)}$ and particle swarm optimization (PSO) ${ }^{32)}$ and other effective methods ${ }^{33,34)}$. Among these techniques, genetic algorithm is the most commonly used one. Genetic algorithm is a stochastic optimization search method that is inspired by Darwin's theory of natural evolution. It can search for a best solution by the evolution of initial population based on the mechanism of natural selection and natural genetics ${ }^{35}$. In the whole process, the fitness function is very important to evaluate the individual's quality. Chapple et al. ${ }^{36)}$ proposed a fitness function in terms of total distortion in a critical region as shown in Eq. (2).

$$
\begin{aligned}
& F=\operatorname{Min}\left(\operatorname{Max}\left(D_{i}\right) \quad \text { if } \mathrm{Si}>\mathrm{T}\right. \\
& \mathrm{i}=1,2,3 \cdots . \mathrm{N} \quad \mathrm{I} \in \mathrm{R}_{\mathrm{c}}
\end{aligned}
$$

Where $D_{i}$ is the total deformation for all nodes $i$ in the critical region $R_{c}, S_{i}$ is the stiffness of the structure and $T$ is the minimum stiffness defined value. Total deformation is computed by the following equation:

$$
D_{i}=\sqrt{d_{x i}^{2}+d_{y i}^{2}+d_{z i}^{2}}
$$

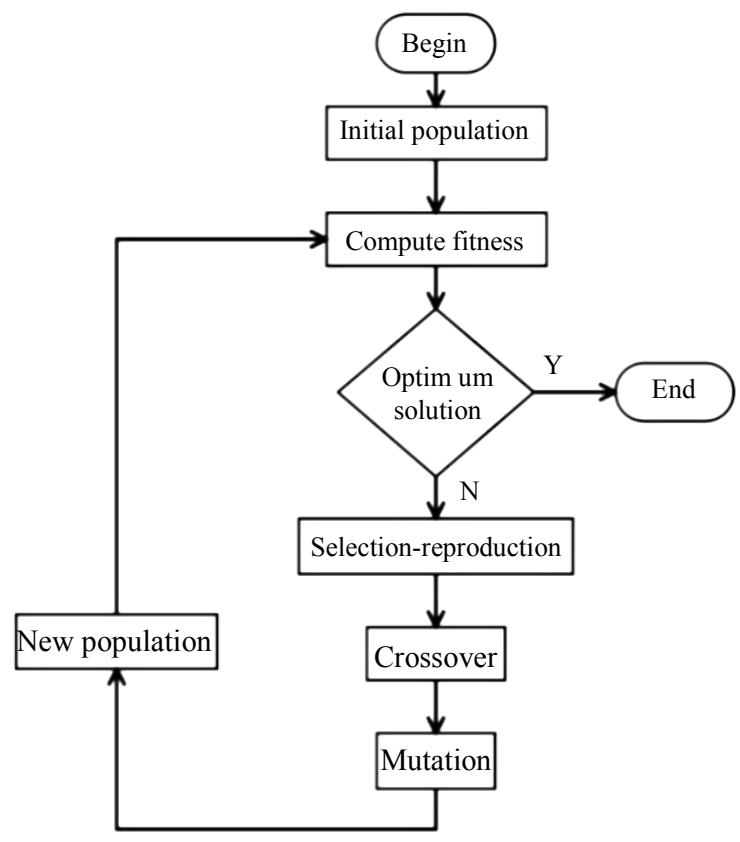

Fig. 9 Flow diagram of genetic algorithm

Where $d_{x i}, d_{y i}$, and $d_{z i}$ are the deformations of node $i$ along $x, y$ and $z$ axis respectively. Other feasible solutions about fitness function have been proposed in relevant published papers ${ }^{37,38)}$. The optimization process of genetic algorithm is shown in Fig. 9.

Recent researches in this area indicate that genetic algorithm (GA) can successfully optimize welding sequence in welded structure to reduce distortion. For example, J. Romero-Hdz et al. ${ }^{37)}$ reported the development and implementation of a genetic algorithm (GA) based on welding sequence optimization in which a structural deformation is computed as a fitness function.

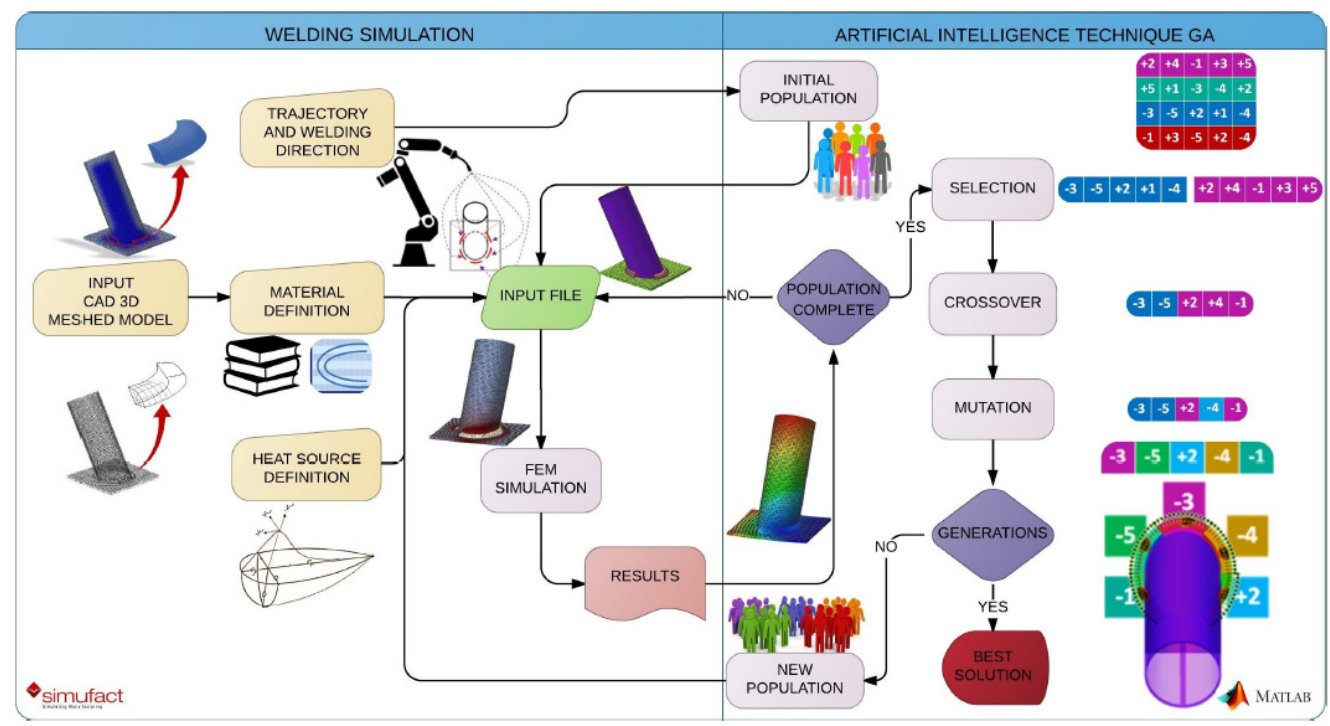

Fig. 10 GA based welding sequence optimization approach ${ }^{37)}$ 


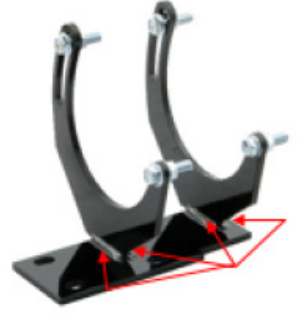

4 weld seams

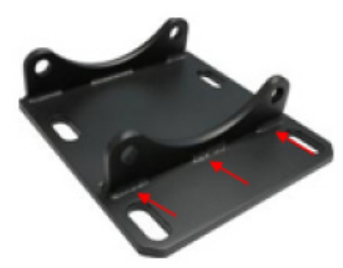

12 weld seams

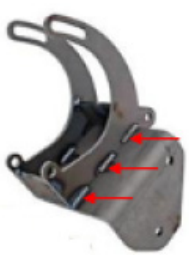

12 weld seams

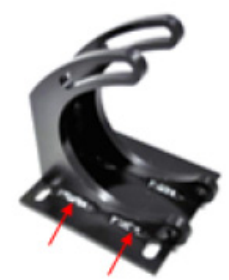

8 weld seams

Fig. 11 Different mounting brackets available in the market as an example of welded parts ${ }^{37)}$

Moreover, a thermo-mechanical finite element analysis (FEA) was used to predict deformation. Fig. 10 presents a flowchart where the description at detail about genetic algorithm based welding sequence optimization approach. In their research, the selected subject of study was a welded mounting bracket, as shown in Fig. 11, which is typically used in telescopic jib, automotive industries, and cars. Its welding distortion is greatly affected by welding sequence. The final results clearly demonstrates that there is considerable difference between the best and worst welding sequence in welding distortion, as shown in Fig. 12. Meanwhile, a real experiment has been carried out to validate the results of GA and FE simulation. The result demonstrates a good agreement between the structural deformation found in real and simulation experiment.

M.B. Mohammed et al. ${ }^{29)}$ presented the optimization procedure of welding sequence to minimize distortion by up to $55 \%$, based on the principles of genetic algorithm and finite element analysis. In addition, the genetic algorithm methods has been utilized with a thermo-mechanical finite element analysis to determine an optimum welding sequence, which was proposed by M.H. Kadivar et al. ${ }^{30)}$. These results of published papers have proven that genetic algorithm (GA) can successfully optimize welding sequence in welded structure to reduce distortion.

However, for welding optimization based on AI tech-

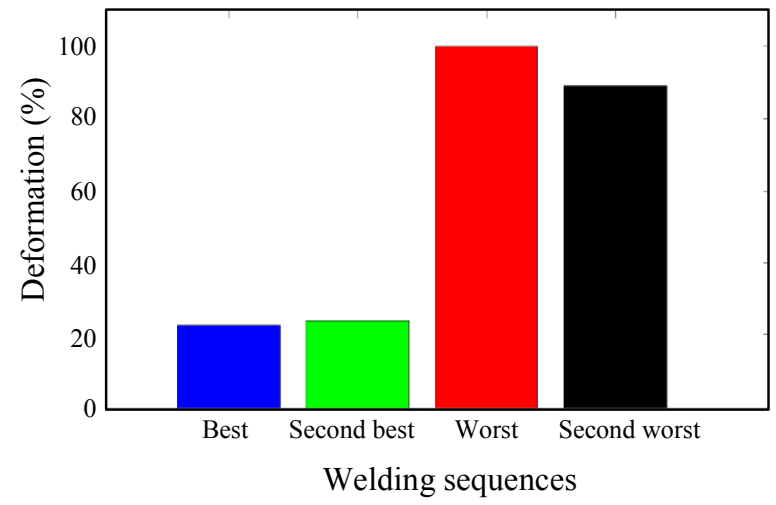

Fig. 12 Deformation reduction of proposed GA ${ }^{37)}$ nology with thermo-elastic-plastic FEM analysis to reduce distortion, excessive computation time and costs for thousands of welding cases will become a huge trouble. In the next stage, rapid and accurate prediction of welding distortion using FEM analysis becomes a critical point. Recently, several methods for decreasing the welding analysis time have been proposed. First, it is the equivalent force and moment method based on inherent strain, which assigns equivalent load to elastic FEM model. The second is the SDB (strain as direct boundary) method based on thermal strain using elastic FEM analysis. These elastic FEM analysis based on inherent strain can dramatically reduce the computation time. Therefore, this approach could be recommended to employ for prediction of welding distortion in the future.

\section{Mechanical and thermal balance}

In fact, in-process control methods have advantages over conventional post weld correction techniques, i.e. the elimination of distortion takes place prior to and during welding process hence avoiding costly reworking operation after welding ${ }^{39)}$. For this purposes, mechanical and thermal balance control methods which employ additional force or heating and cooling source was used.

By G. Fu et al. ${ }^{40)}$ a sequentially coupled thermal and mechanical 3D finite element (FE) model is developed to investigate the effect of boundary conditions on residual stress and distortion in T-joint welds. The results show that the transverse residual stress, vertical displacement, angular distortion and transverse shrinkage depend significantly on the mechanical boundary conditions. J.U. Park et al. ${ }^{41)}$ studied the effects of the magnitude, the direction, and the release time of pre-tensioning stress caused by external load on welding distortion and residual stress in fillet welding using the thermo-elastic-plastic analysis. And then, the effectiveness of reduction of distortion by pre-tensioning method gotten via the analysis is verified by experiment. Although mechanical balance control technique is an effective 


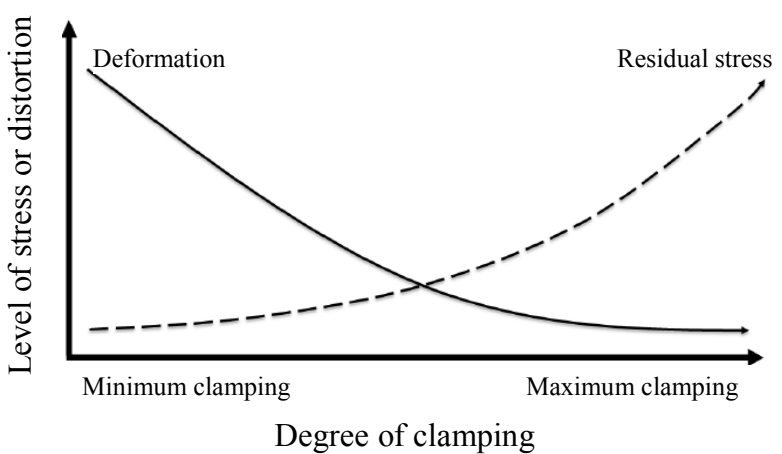

Fig. 13 The relationship between the level of stress and distortion and degree of clamping ${ }^{42}$

method, it also has a large disadvantage that high welding residual stresses could be caused by strong external constrains. Residual stresses and distortion are strongly linked as shown in Fig. 13 ${ }^{42}$. However, high residual stress can have bad effect on fatigue performance of welded structure. To order to remove this hidden danger, thermal balance control methods have been developed.

In fact, thermal balance in-process control methods which employ additional heating with and without cooling sources during welding process are more desirable than those based on mechanical techniques ${ }^{43)}$. This is because thermal stretching generated by differential heating is more efficient compared to mechanical stretching which requires complex setup and large forces for large structures.

The application of thermal effect for mitigating weld distortion and residual stress prior to and during welding was first reported by Burak et al. ${ }^{44,45)}$ who developed thermal tensioning method, often known as static thermal tensioning (STT). The STT treatments were carried out by locating a cooling system underneath the weld zone and simultaneously, both regions away from the weld zone were heated using resistive heating bands at various temperatures of $100{ }^{\circ} \mathrm{C}, 200{ }^{\circ} \mathrm{C}$ and $300{ }^{\circ} \mathrm{C}$ to generate thermal gradient, as shown in Fig. $14^{43)}$. The results show that the use of cooling or quenching at the weld region and additional heating sources away from the weld region modifies the weld thermal cycles and temperature fields. The peak temperature around the weld zone under cooling system only is lower than the as welded condition. As a result of this, the use of quenching only during welding reduces the out of plane distortion.

An in-process method for controlling welding distortion in fillet welds is developed by M. Mochizuki et al. ${ }^{39)}$. Schematic illustration of the proposed method is shown in Fig. 15. It particularly reduces angular distortion by performing reverse-side tungsten inert gas (TIG) heating of the weld line at a fixed distance ahead

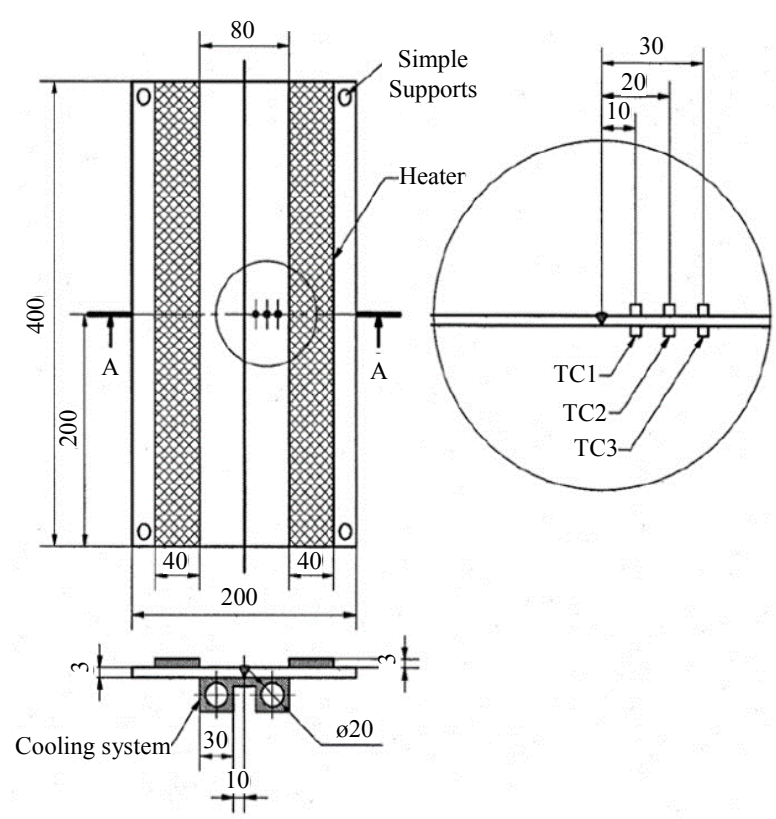

Fig. 14 Experimental setup for a MIG-welding process with STT treatment facilities ${ }^{43}$ )

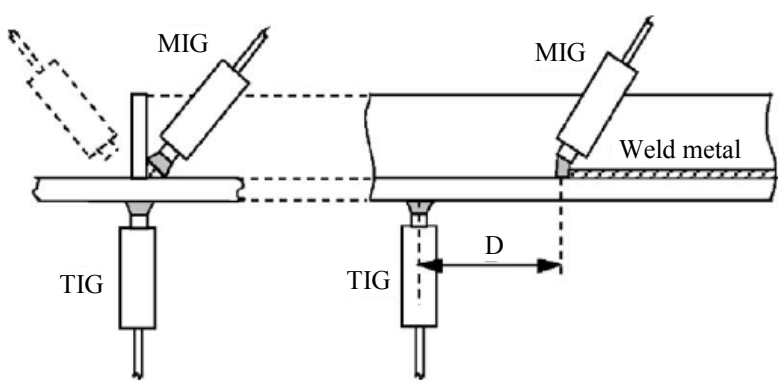

Fig. 15 Schematic illustration of welding distortion control by reverse-side heating ${ }^{39)}$

of metal inert gas (MIG) welding during the weld process. Various heating conditions are examined by experiment and by the finite-element analysis in order to determine appropriate conditions and to study the mechanism by which welding distortion is reduced. It is consequently found that this mechanism is a result of two main effects: TIG heating effect on the reverse side, which produces the opposite angular distortion, and preheating effect.

S.M. Joo et al. ${ }^{46)}$ investigated the effect of trailing heat sink on welding residual stress and out-of-plane displacement using the finite element analysis (FEA), shown as Fig. 16. This numerical simulation indicated that compared to conventional welding, trailing heat sink welding showed, first, smaller deformation and residual stress, second, a significantly reduced out-of-plane displacement under optimal heat sink welding conditions, and third, a reduced overall residual stress developed although no significant differences were seen 


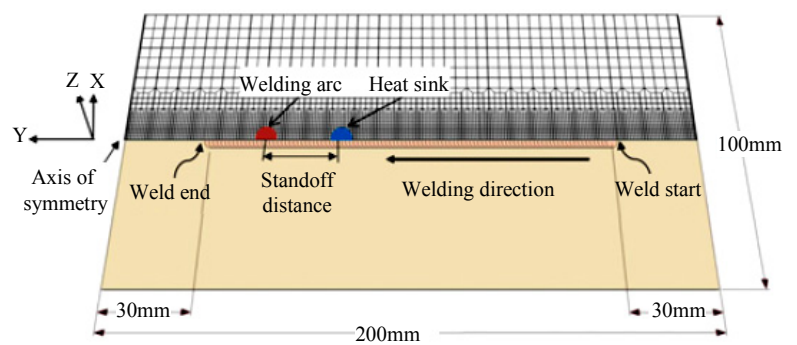

Fig. 16 Finite element mesh of model and coordinate system $^{46)}$

in the maximum values of welding residual stress. Reasons for reducing weld deformation is that the effect of heat sink could prevent the development of the plastic strain near weld zone during welding process.

\section{Conclusion}

In this paper, various methods for mitigation of welding-induced distortion based on finite element analysis in design stage and manufacturing stage are studied and reviewed. Based on the results of these works, we can draw the following conclusions.

1) If possible, at the design stage, adopting reasonable structural planning or other means can have obvious cost benefits for limiting welding distortion. It is because it can prevent the distortion at the source of formation in welded structures. Common approaches include groove welding, tack welding, pre-heating or post-heating and pre-shaping methods.

2) It is believed that choosing the optimum welding process parameters is more effective approach for reducing welding distortion during manufacturing process. The summary of research works performed shows that both conventional methods and AI techniques can solve the parametric optimization problems. According to the number of parameters in practical problems, a suitable parameter optimization method is selected to reduce welding distortion.

3) For welded structures with a number of weld seams, welding sequence and direction have a strong influences on weld deformation. Genetic algorithm can successfully optimize welding sequence to minimize the welding distortion.

4) In order to reduce exorbitant computation time and cost for TEP-FEM analysis, inherent strain method based on elastic FEM could be adopted to predict welding distortion during welding optimization with AI technology in the next stage.

5) Mechanical balance control methods was also commonly used to reduce welding distortion during welding process, which employ large force. However, it can generate large welding residual stress because of strong external constrains, which has bad effect on fatigue performance of welded structure

6) In order to get rid of the disadvantages of mechanical balancing, thermal balance in-process control methods have been developed, which employ additional heating with and without cooling sources during welding process. It is more desirable than mechanical techniques, because mechanical stretching requires complex setup and large force for large structures.

7) It would be more effective to mitigate welding distortion if we can adopt multiple approaches simultaneously, such as groove design, welding sequence optimization and reheating. It is valuable to search the best plan and design using FEM analysis before welding.

8) A review on various techniques to mitigate the welding distortion based on FEM analysis was presented. It is useful to fully understand the main mechanism of mitigation of welding distortion and to choose the most suitable method for minimizing distortion according to the realistic fabrication demand.

ORCID: Chunbiao Wu: http://orcid.org/0000-0001-6365-443X ORCID: Jae-Woong Kim: http://orcid.org/0000-0003-0291-0844

\section{References}

1. Y.H. Manurung, R.N. Lidam, M.R. Rahim, M.Y. Zakaria, M.R. Redza and M.S. Sulaiman, G. Tham, S. Abas, Welding distortion analysis of multipass joint combination with different sequences using 3D FEM and experiment, Int. J. Press. Vessel. Pip. 111-112 (2013) 89-98. https://doi.org/10.1016/j.ijpvp.2013.05.002

2. K. Masubuchi, Analysis of welded structures, residual stresses, distortion, and their consequences, Pergamon Press, New York, USA (1980).

3. D. Deng and H. Murakawa, Prediction of welding distortion and residual stress in a thin plate butt-welded joint, Comput. Mater. Sci. 43(2) (2008) 353-365. https://doi.org/10.1016/j.commatsci.2007.12.006

4. Y. Ueda and T. Yamakawa, Analysis of thermal elasticplastic stress and strain during welding by finite element method, trans. Japan Weld. Soc. 2(2) (1971) 186-196. https://doi.org/10.2207/qijws1943.42.567

5. D. Deng, Y. Zhou, T. Bi and X. Liu, Experimental and numerical investigations of welding distortion induced by $\mathrm{CO}_{2}$ gas arc welding in thin-plate bead-on joints, Mater. Des. 52(2013) 720-729.

https://doi.org/10.1016/j.matdes.2013.06.013

6. C. Wang, Y. R. Kim and J. W. Kim, Comparison of FE models to predict the welding distortion in T-joint gas metal arc welding process, Int. J. Precis. Eng. Manuf. 15(8) (2014) 1631-1637. https://doi.org/10.1007/s12541-014-0513-8 
7. D. Deng, W. Liang and H. Murakawa, Determination of welding deformation in fillet-welded joint by means of numerical simulation and comparison with experimental measurements, J. Mater. Process. Technol. 183(2007) 219225.

https://doi.org/10.1016/j.jmatprotec.2006.10.013

8. C. Wu and J. Kim, Analysis of welding residual stress formation behavior during circumferential TIG welding of a pipe, Thin Walled Struct. 132 (2018) 421-430.

https://doi.org/10.1016/j.tws.2018.09.020

9. R.N. Lidam, Y.H. Manurung, E. Haruman, M. Redza, M. Rahim, M, Sulaiman, M. Zakaria, G. Tham, S. Abas and C.Y. Chau, Angular distortion analysis of the multipass welding process on combined joint types using thermo-elastic-plastic FEM with experimental validation, Int. J. Adv. Manuf. Technol. 69 (9-12) (2013) 2373-2386. https://doi.org/10.1007/s00170-013-5184-6

10. J. M. Lee, H. D. Seo and H. Chung, Efficient welding distortion analysis method for large welded structures, J. Mater. Proc. Tech. 256 (2018) 36-50. https://doi.org/10.1016/j.jmatprotec.2018.01.043

11. D. Deng, H. Murakawa and W. Liang, Numerical simulation of welding distortion in large structures, Comput. Methods Appl. Mech. Eng. 196(45-48) (2007) 46134627.

https://doi.org/10.1016/j.cma.2007.05.023

12. J. Wang, S. Rashed and H. Murakawa, Mechanism investigation of welding induced buckling using inherent deformation method, Thin-Walled Struct., 80 (2014) 103-119. https://doi.org/10.1016/j.tws.2014.03.003

13. J.-S. Lee, Welding deformation analysis of plates using the inherent strain-based equivalent load method, $J$. Korean Weld. Join. 28 (2) (2010) 39-46. https://doi.org/10.5781/KWJS.2010.28.2.039

14. Y. Ha, S. Cho and T. Jang, Developmen of welding distortion analysis method using residual strain as boundary condition, Mater. Sci. Forum. 580-582 (2008) 649-654. https://doi.org/10.4028/www.scientific.net/MSF.580 $-582.649$

15. M. Kim, M. Kang and H. Chung, Simplified welding distortion analysis for fillet welding using composite shell elements, Int. J. Nav. Archit. Ocean Eng. 7(3) (2015) 452-465. https://doi.org/10.1515/ijnaoe-2015-0032

16. J. Heo, Y. Li and J. H. Lee, Prediction of plate thermal deformation by multi-line heating using SDB method based on thermal strain, J. Weld. Join. 37(1) (2019) 40-45. https://doi.org/10.5781/JWJ.2019.37.1.5

17. P. Michaleris, Minimization of welding distortion and bucklin, modeling and implementation, 1st Edition, Woodhead publishing, Cambridge, United Kingdom (2011).

18. D. Deng and H. Murakawa, FEM prediction of buckling distortion induced by welding in thin plate panel structures, Comput. Mater. Sci. 43(4) (2008) 591-607. https://doi.org/10.1016/j.commatsci.2008.01.003

19. Y. Ye, J. Cai, X. Jiang, D. Dai and D. Deng, Influence of groove type on welding-induced residual stress, deformation and width of sensitization region in a SUS304 steel butt welded joint, Adv. Eng. Softw. 86(2015) 39-48. https://doi.org/10.1016/j.advengsoft.2015.04.001

20. D. Camilleri, T.G.F. Gray and N. McPherson, Optimizing tack welding fabrication procedures using numerical finite element models, J. Ship Prod. 26 (2010) 117-134.

21. M. Abid and M. Siddique, Numerical simulation to study the effect of tack welds and root gap on welding deformations and residual stresses of a pipe-flange joint, Int. J. Press. Vessels Pip. 82(2005) 860-871. https://doi.org/10.1016/j.ijpvp.2005.06.008

22. C. Heinzea, C. Schwenka and M. Rethmeier, The effect of tack welding on numerically calculated welding-induced distortion, J. Mater. Proc. Technol. 212 (2012)308-314. https://doi.org/10.1016/j.jmatprotec.2011.09.016

23. R.V. Preston, Ph. D. thesis, Modelling of residual stresses in welded aerospace alloys, University of Cambridge, Cambridge, United Kingdom (2000).

24. M. T. Hayajneh, A. F. Al-Dwairi, and S. F. Obeidat, Optimization and control of bending distortion of submerged arc welding I-beams, J. Constructional Steel Res. 142 (2018) 78-85. https://doi.org/10.1016/j.jcsr.2017.12.012

25. M. Islam, A. Buijk, M. Rais-Rohani and K. Motoyama, Simulation- based numerical optimization of arc welding process for reduced distortion in welded structures, Finite Elements in Anal. Des. 84(2014) 54-64. https://doi.org/10.1016/j.finel.2014.02.003

26. G.M Fu, M.I Lourenço, M.I Duan and S. F. Estefen, Influence of the welding sequence on residual stress and distortion of fillet welded structures, Mar. Struct. 46 (2016) 30-55. https://doi.org//10.1016/j.marstruc.2015.12.001

27. D. A. Kumar, N. R. Mandal and M. M. Mahapatra, A study on the effect of welding sequence in fabrication of large stiffened plate panels, J. Mar. Sci. Appl. 10(4) (2011) 429-436. https://doi.org/10.1007/s11804-011-1088-8

28. M. Moradi and H. Pasternak, A study on the influence of various welding sequence schemes on the gain in strength of square hollow section steel T-joint, J. Weld. Join. 35(4) (2017) 41-50. https://doi.org/10.5781/JWJ.2017.35.4.7

29. M. B. Mohammed, W. Sun and T. H. Hyde, Welding sequence optimization of plasma arc for welded thin structures, Comput, Aided Optim. Des. Eng. XII. 125 (2012) 231-242.

https://doi.org/10.2495/OP120201

30. M. H. Kadiver, K. Jafarpur and G.H. Baradaran, Optimizing 
welding sequence with genetic algorithm, Computational Mech. 26 (2000) 514-519.

https://doi.org/10.1007/s004660000195

31. S. Fukuda and K. Yoshikawa, Determination of welding sequence, a neural net approach, Eng. Anal. Boundary Elements. 7(2) (1990) 78-82. https://doi.org/10.1016/0955-7997(90)90024-4

32. X.-W. Wang, Y.-P. Shi, X.-S. Gu and D.-Y. Ding, Partition mutation PSO for welding robot path optimization. Springer Int. Publishing. (2015) 77-86. https://doi.org/10.1007/978-3-319-18997-0_6

33. J. Romero-Hdz, B. N. Saha, G. Toledo, Welding sequence optimization through a modified lowest cost search algorithm, Comput. Sci. Eng. 6(2) 2016, 25-32. https://doi.org/10.5923/j.computer.20160602.02

34. I. Voutchkov, A.J. Keane, A. Bhaskar and Tor M. Olsen, Weld sequence optimization: The use of surrogate models for solving sequential combinatorial problems, Comput. Method Appl. M. 194 (2005) 3535-3551. https://doi.org/10.1016/j.cma.2005.02.003

35. D. E. Goldberg, Genetic algorithms in search, optimization and machine learning, 1st Edition. Addison Wesley Publishing Co., Boston, USA (1989).

36. A. Chapple, Z. Tahir and F. Jardine, Weld Distortion Optimisation using HyperStudy, The 8th UK Altair Techn. Conf. (2013) 1-13.

37. J. Romero-Hdz, S. Aranda, G. Toledo-Ramirez, J. Segura and B. Saha, An elitism based genetic algorithm for welding sequence optimization to reduce deformation, Res. Computing Sci. 121 (2016) 17-36.

38. Y. G. Liao, Optimal design of weld pattern in sheet metal assembly based on a genetic algorithm, Int. J. Adv. Manuf. Technol. 26 (5-6) (2005) 512-516. https://doi.org/10.1007/s00170-003-2003-5
39. M. Mochizuki and M. Toyoda, Weld distortion control during welding process with reverse-side heating, $J$. Eng. Mater. Technol. 129 (2007) 265-270. https://doi.org/10.1115/1.2400275

40. G. Fu, M. I. Lourenco, M. Duan and S. F. Estefen, Effect of boundary conditions on residual stress and distortion in T-joint welds, J. Constructional Steel Res. 102 (2014) 121-135. https://doi.org/10.1016/j.jcsr.2014.07.008

41. J. U. Park, G. B. An and H. W. Lee, Effect of external load on angular distortion in fillet welding, Mater. Des. 42 (2012) 403-410. https://doi.org/10.1016/j.matdes.2012.06.006

42. H. Porzner, Possibilities of numerical simulation for evaluation and optimization of welded designs, Principles, Mathematical Modelling of Weld Phenomena, 738 (2001) 701-724.

43. M. N. Ilman, Kusmono, M. R. Muslih, N. Subeki and H. Wibowo, Mitigating distortion and residual stress by static thermal tensioning to improve fatigue crack growth performance of MIG AA5083 welds, Mater. Des. 99 (2016) 273-283. https://doi.org/10.1016/j.matdes.2016.03.049

44. YaI Burak, L.P. Bisijina, YaP Romanjuk, A.A. Kazimirov, V.P. Morgun, Controlling the longitudinal plastic shrinkage of metal during welding, Avtom. Svarka. 288 (3) (1977) 27-29.

45. Ya. I. Burak, Ya. P. Romanjuk, A. A. Kazimirov and V. P. Morgun, Selection of the optimum fields for preheating plates before welding, Avtom. Svarka. 314 (5) (1979) 5-9.

46. S. M. Joo, H. S. Bang, H. S. Bang and K. S. Park, Numerical Investigation on Welding Residual Stress and out-of-plane displacement during the heat sink welding process of thin stainless steel sheets, Int. J. Precis. Eng. Manuf. 17(1) (2016) 65-72. https://doi.org/10.1007/s12541-016-0009-9 